\title{
Variations in teaching of removable partial dentures in Spanish dental schools
}

\author{
Raquel Castillo de Oyagüe ${ }^{1}$, Christopher Lynch ${ }^{2}$
}

${ }^{1}$ DDS, PhD, Associate Professor, Department of Prosthodontics, School of Dentistry, Complutense University of Madrid (UCM), 28040, Madrid, Spain

${ }^{2}$ BDS, PhD, MFD RCSI, FDS (Rest Dent) RCSI, Senior Lecturer/Consultant, Department of Adult Dental Health, School of Dentistry, Cardiff University, CF14 4XY, Cardiff, Wales, UK

Correspondence:

Department of Prosthodontics.

School of Dentistry.

Complutense University of Madrid, U.C.M.

Pza. Ramón y Cajal n ${ }^{\circ}$,

C.P.: 28040, Madrid, Spain.

raquel.castillo@odon.ucm.es

Castillo de Oyagüe R, Lynch C. Variations in teaching of removable partial dentures in Spanish dental schools. Med Oral Patol Oral Cir Bucal. 2011 Nov 1;16 (7):e1005-13.

http://www.medicinaoral.com/medoralfree01/v16i7/medoralv16i7p1005.pdf

Received: 29/10/2010 Accepted: $16 / 01 / 2011$

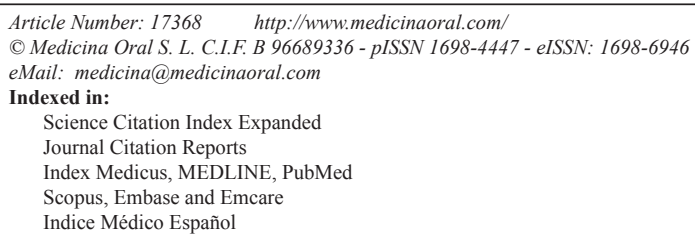

\begin{abstract}
Objectives: Despite the increasing demand for implant-based treatments, removable partial dentures (RPDs) are frequently used in the oral rehabilitation of partially dentate patients. Furthermore, the Bologna Declaration Agreement (1999) promotes the freedom of movement both of students among dental schools and of graduates across the European Union (EU). Given that inconsistency in teaching among dental schools may lead to confusion, this study aimed to evaluate the status of teaching and clinical experience reached by undergraduate dental students in Spanish dental schools in relation to RPDs.

Study design: A questionnaire seeking information on the preclinical and clinical teaching of RPDs was emailed to all Spanish dental schools (11 public, 4 private) with complete undergraduate degree dental programmes in November 2009. Descriptive statistical data analysis was performed.

Results: A 100\% response rate was obtained. The average duration of the preclinical course in Spain was 44 hours ( 38 hours in the public schools and 60.5 hours in the private schools). However, public schools reported a greater number of RPDs made per student prior to graduation, with an average of 3.4 acrylic (range: 1-20) and 3.4 cobaltchromium (range: 1-20) RPDs. The corresponding means for private schools were 1 acrylic (range: 0-2) and 2.3 cobalt-chromium (range: 1-4). One public school (9\%) stated that they were teaching RPDs using Problem-BasedLearning.

Conclusions: Similar to that noted in previously surveyed countries, variations in teaching programmes and clinical experience concerning RPDs achieved by Spanish dental students were evident. While diversity of teaching is often considered to be of benefit, dental students must be adequately trained to ensure that they meet the needs of the patients they will serve during their careers.
\end{abstract}

Key words: Dental education, questionnaires, removable partial dentures, removable prosthodontics, teaching methods. 


\section{Introduction}

As teeth are lost the structural integrity of the dental arch is disrupted with a subsequent realignment of the remaining teeth until a new equilibrium position is established. Notwithstanding recent advances in preventive dentistry (1), a recent report showed that there will be a large and growing need for fixed and removable prosthetic treatments in the future, mainly due to the substantial growth of population and their extended life expectancy (2).

Suitable treatment options for partially dentate patients include implant-based treatments, conventional fixed partial prostheses, or removable partial dentures. Vanzeveren et al. (3) conducted a longitudinal study to assess the effectiveness of oral rehabilitations using removable partial dentures (RPDs), noting these to be effective and non-deleterious to oral health. Regardless of the increasing demand for implant-based restorations, RPDs offer the advantages of avoiding the surgical risks, complexity and costs associated with implant treatments $(4,5)$. Nevertheless, for some many years, it has been recognized that problems exist among the dental profession when prescribing, designing, and fabricating removable partial dentures (6-9), despite the introduction of the European Union's "Medical Devices Directive" in 1993. This Directive placed specific requirements on dental practitioners "to provide adequate written instructions when a prosthesis is being manufactured, and that dental laboratories manufacture the prosthesis to this specification".

It has been reported that approximately $60 \%$ of master impressions received by dental laboratories for the construction of RPDs have little or no input from dentists into to the design of the planned prostheses $(6,7,10,11)$. Bearing in mind the importance of dentists designing the RPDs themselves (12) and the harmful effects of poorly designed prostheses in terms of the development of caries or periodontal disease (13); such results reveal a clearly worldwide insufficiency in this area of dental education and practice (14). Let alone this, there is some evidence that inadequately designed RPDs are badly tolerated by patients (15).

Dental undergraduate programmes must continually evaluate their portion of the removable prosthodontic curricula to ensure that the current therapeutic and technical goals related to the dental health needs of society are being met $(1,16)$. In this regard, previous investigations on teaching of removable partial dentures have been conducted in the United States (US) $(16,17)$, and Ireland and the United Kingdom (UK) (18). These studies showed a wide variation in the theoretical principles taught and the clinical skills attained by undergraduate students within and between the surveyed countries. Hence, noticeable disparities in learning systems among different countries have made it necessary to audit and confirm that the basic clinical skills have actually been achieved by the time the students complete their dental school education $(19,20)$. Unlike what happens in the UK -where a vocational training period (VT) is mandatory for new graduated dental students to be qualified-, recently graduated dentists in other countries worldwide, such as Spain, become directly responsible on graduation for the care of their patients, including treatment planning and design of RPDs.

The Bologna Declaration Agreement (1999) promotes the freedom of movement both of students among dental schools and of graduates across the 27 countries of the European Union (EU) $(21,22)$. Therefore, inconsistency in teaching among dental schools may lead to confusion amongst new dentists (18).

Given the existing demand for removable partial dentures in dental practice and the need to ensure that dentists are skilled to offer the best possible care to their patients, this study aimed to evaluate the differences in teaching methods and clinical experience achieved by undergraduate dental students in Spain in relation to RPDs immediately before the Bologna reform introduction. The period the study has been carried out is crucial and so are the results, as the deadline to achieve the Convergence in Higher Education in the European Union was specifically settled for 2010 .

\section{Materials and Methods}

In November 2009, a questionnaire was emailed to the Professor responsible for delivering teaching of Prosthetic Dentistry in each of the 15 dental schools in Spain (11 public schools and 4 private), having complete undergraduate dental degree programmes.

The questionnaire sought information relating to the preclinical and clinical teaching of RPDs within each school. The questionnaire included both "closed" questions (where respondents were given a number of possible responses to a statement and asked to identify the most appropriate one), and "opened" questions (where respondents were given some space in which to write a textual response to a statement). Subjects investigated in the questionnaire included:

- Duration and timing of the preclinical and clinical courses on RPDs.

- The person responsible for directing and delivering teaching programmes for RPDs (an explanation of the teachers' profiles in Spanish universities is outlined in Figure 1).

- Teaching of various aspects of RPDs such as tooth preparations, use of a dental surveyor, prescription writing, impression techniques, and use of articulators.

- Interaction with internal and external laboratories.

- Amounts of clinical treatments completed by students.

- Suitability of patient pool for student treatment. 


\begin{tabular}{|c|c|}
\hline Position & Features \\
\hline Cathedratic Professor & $\begin{array}{l}\text { Tenured full-time position, holds a } \mathrm{PhD} \text { and has an international research profile. } \\
\text { May serve as Departmental Chairman or even University President. } \\
\text { A significant research output of international significance is necessary for this position. } \\
\text { Clinical specialist accreditation is necessary for this post in dentistry. }\end{array}$ \\
\hline Professor & $\begin{array}{l}\text { Tenured full-time position, holds a } \mathrm{PhD} \text { and has an international research profile. } \\
\text { Clinical specialist accreditation is necessary for this post in dentistry. }\end{array}$ \\
\hline Contracted Doctor & $\begin{array}{l}\text { Tenured full-time position, holds a } \mathrm{PhD} \text { and has some international research profile. } \\
\text { Clinical specialist accreditation is necessary for this post in dentistry. }\end{array}$ \\
\hline Assistant Doctor & $\begin{array}{l}\text { Non-tenured, full-time position, holds a } \mathrm{PhD} \text { (this post is typically held for up to } 3 \text { years } \\
\text { to allow the post-holder develop a research profile suitable to be a Professor). }\end{array}$ \\
\hline Associate Professor & $\begin{array}{l}\text { May be tenured, part-time position, no } \mathrm{PhD} \text { is required. } \\
\text { Main emphasis of this position is for teaching. }\end{array}$ \\
\hline $\begin{array}{l}\text { Honorary Teaching } \\
\text { Assistant }\end{array}$ & Part-time teacher, usually a PhD student. \\
\hline
\end{tabular}

Fig. 1. Profiles of teachers in Spanish dental schools.

- Preclinical and clinical assessments.

- Perceived challenges to the teaching of RPDs.

Confidentiality was maintained. Information received was entered onto a Microsoft Excel XP (Microsoft Office; Washington, US) spreadsheet. Descriptive statistical data analysis was performed. Percentages were also calculated. No questionnaires had to be eliminated from this study since all of the items were properly filled out in each case.

\section{Results}

Fifteen completed questionnaires were returned (response rate: 100\%). Approximately 1060 dentists graduate from Spanish dental schools per year (645 from public schools and 415 from private schools). *Preclinical teaching of removable partial dentures -Nature of the preclinical course in removable partial dentures
All fifteen schools reported that they had a specific preclinical course for teaching removable partial dentures. In eleven $(73 \%)$ of the responding schools, this occurred in the third year of the dental programme. In three schools (20\%), the preclinical course was held in the fourth year. In the remaining school (7\%) the preclinical programme was delivered over two years (third and fourth year).

The average duration of the complete preclinical course (theoretical and practical) was 38 hours (range: 12-120) in the public schools and 60.5 hours (range: 20-116) in the private schools. Considering all of the surveyed schools, the total average duration of the complete preclinical course was 44 hours (range: 12-120). Differences were also detected between public and private schools in relation to the way in which these hours were distributed. In the public schools, the average time dedi- 
cated to the preclinical practical course was 16.6 hours (range: 5-60, apart from one school having no preclinical practical course), while the corresponding figure in the private schools was 32.6 hours (range: 6-72). Moreover, differences in preclinical didactic teaching were examined and it was found that the average time for formal lectures on RPDs was 14.2 hours (range: 4-30) in the public schools and 25.2 hours (range: 14-35) in the private schools. The average time for tutorials and seminars was 5.8 hours (range: $0-40$ ) in the public schools and 10.1 hours (range: $0-30$ ) in the private schools.

One public school $(9 \%)$ reported that they dedicated 8 hours for Problem-Based-Learning (PBL) in terms of treatment planning and designing RPDs for clinical case examples. After that, students discussed possible case solutions in group in presence of the Professor (4 more hours).

The person with overall responsibility for directing the preclinical course in removable partial dentures is displayed in table 1. Regardless of the differences in the academic professional category of the person in charge, the public dental schools showed better staff: student ratios for lectures and lab demonstrations, while private schools reported improved ratios for tutorials (Table 2). -Certain aspects taught in the preclinical course in removable partial dentures

All of the private schools reported that their students were taught how to use a surveyor during the preclinical course, whereas four (36\%) of the eleven public schools did not teach their students on this topic. The average time spent on teaching the use of the surveyor and denture design (including lectures, tutorials, practical experience) was 3.8 hours (range: $0-10$ hours), without obvious differences between public and private schools. Three of the public schools (27\%) and three of the private schools $(75 \%)$ reported that their students were taught how to complete tooth preparations on patient simulator units as part of the preclinical course.

With respect to the teaching of prescription writing for removable partial dentures, thirteen dental schools (87\%) taught prescription writing via formal lectures, delivering around one hour each (mean: 1.2 hours). In addition, one $(9 \%)$ of the public and one $(25 \%)$ of the private schools dedicated a mean of 1.5 hours (range: 1-2) for tutorials/seminars on prescription writing.

All of the dental schools reported that they teach on the use of semi-adjustable articulators, despite the wide variation in the articulator type and commercial brands within the responding dental schools. Four of the schools (27\%) use the Dentatus articulator (A.B. Dentatus, Stockholm, Sweden); three schools (20\%) use the Artex (Girrbach Dental GMBH, Pforzheim, Germany); three schools (20\%) use the Quick Master (FAG Dentaire, Cluses, France); three schools (20\%) use the Stratos (Ivoclar Vivadent A.G., Schaän, Liechtestein); two schools (13\%) use the Protar (Kavo Dental GMBH,

Table 1. Person with responsibility for: a) overall direction of the preclinical course in removable partial dentures (RPDs); b) teaching tooth preparations on phantom-heads; c) the use of the surveyor when designing RPDs; d) RPD prescription writing.

\begin{tabular}{|c|c|c|c|c|c|c|c|c|c|c|c|c|}
\hline & \multicolumn{3}{|c|}{$\begin{array}{l}\text { Overall preclinical } \\
\text { RPD-course Director }\end{array}$} & \multicolumn{3}{|c|}{$\begin{array}{c}\text { Tooth preparations on } \\
\text { phantom-heads }\end{array}$} & \multicolumn{3}{|c|}{ Use of the Surveyor } & \multicolumn{3}{|c|}{ Prescription writing } \\
\hline & Pub & Priv & Total & Pub & Priv & Total & Pub & Priv & Total & Pub & Priv & Total \\
\hline $\begin{array}{l}\text { Cathedratic } \\
\text { Professor } \\
\text { and/or } \\
\text { Professor* }\end{array}$ & 8 & - & 8 & 2 & 1 & 3 & 4 & 1 & 5 & 7 & 1 & 8 \\
\hline $\begin{array}{l}\text { Contracted } \\
\text { Doctor* }\end{array}$ & - & - & - & - & - & - & 2 & - & 2 & - & - & - \\
\hline $\begin{array}{l}\text { Associate } \\
\text { Professor* }\end{array}$ & 3 & 4 & 7 & 2 & 3 & 5 & 4 & 4 & 8 & 3 & 4 & 7 \\
\hline
\end{tabular}

Pub= public dental schools; Priv = private dental schools; Total= both public and private dental schools

*The Professors' profiles in Spain are described in Figure 1. 
Table 2. Staff: student ratio for teaching of the preclinical course in removable partial dentures, and supervisory ratio for the clinical sessions.

\section{Median (range) of staff: student ratio for the}

preclinical course and clinical sessions on RPDs

\begin{tabular}{lccc}
\hline & Public & Private & TOTAL \\
\hline For preclinical lectures & $1 / 53(1 / 13-1 / 100)$ & $1 / 75(1 / 30-1 / 120)$ & $1 / 59(1 / 13-1 / 120)$ \\
For tutorials & $1 / 12(0-1 / 28)$ & $1 / 3(0-1 / 10)$ & $1 / 9(0-1 / 28)$ \\
For lab demos & $1 / 9(0-1 / 28)$ & $1 / 14(1 / 1-1 / 30)$ & $1 / 11(0-1 / 30)$ \\
& $1 / 17(1 / 4-1 / 100)$ & $1 / 7(1 / 4-1 / 10)$ & $1 / 15(1 / 4-1 / 100)$
\end{tabular}

Table 3. Aspects of removable partial denture design and fabrication examined at the end of the preclinical and clinical courses.

\begin{tabular}{|c|c|c|c|c|c|c|}
\hline & \multicolumn{3}{|c|}{$\begin{array}{l}\text { Examination at the end } \\
\text { of the preclinical course }\end{array}$} & \multicolumn{3}{|c|}{$\begin{array}{l}\text { Examination at the end } \\
\text { of the clinical course }\end{array}$} \\
\hline & Pub & Priv & Total & Pub & Priv & Total \\
\hline Surveying \& design & 8 & 3 & 11 & 9 & 4 & 13 \\
\hline Rest seat preparation & 2 & 3 & 5 & 6 & 4 & 10 \\
\hline Impression technique & 4 & 2 & 6 & 8 & 3 & 11 \\
\hline Mounting of casts in articulator & 5 & 3 & 8 & 8 & 4 & 12 \\
\hline Prescription writing & 5 & - & 5 & 9 & 3 & 12 \\
\hline Try-in plus delivery & - & - & - & 6 & 4 & 10 \\
\hline
\end{tabular}

$\mathrm{Pub}=$ public dental schools; Priv $=$ private dental schools; Total $=$ both public and private dental schools.

* Some schools selected more than one option. 
Biberach, Germany); two schools (13\%) use the Whip mix (Whip Mix Europe GmbH, Dortmund, Germany); one school (7\%) use the Bio-Art (Bio-Art LTDA., Sao Paulo, Brasil); one school (7\%) use the Quick Perfect (FAG Dentaire, Cluses, France); and one school (7\%) use the SAM Articulator (Great Lakes Orthodontics, Ltd., NY, US).

Ten public (91\%) and three private (75\%) schools reported that they had an evaluation at the end of the preclinical course. In seven public (64\%) and three private schools $(75 \%)$, this examination included both written and practical assessments. In two public schools (18\%) only a practical assessment was made, while in one public school $(9 \%)$ it just took the form of a written examination. The aspects of removable partial denture design and fabrication evaluated are reported in table 3 . None of the private dental schools incorporated an exam on prescription writing.

-Clinical teaching of removable partial dentures

In all of the surveyed schools, students had dedicated clinical sessions for the provision and delivery of removable partial dentures. Eight dental schools (53\%) reported that students commenced treatment of patients with removable partial dentures in Year 4; in five schools $(33 \%)$ students commenced this treatment in Year 5; and in two other schools (13\%) in Year 3. There was "paired teaching" for clinical sessions in fourteen (93\%) respondent schools. In one public school (9\%) the students worked in groups of three. In general, the private dental schools reported better staff: student ratios for clinical sessions (Table 2). Except for one public (9\%) and one private school (25\%), students usually began treatment of partially dentate patients requiring removable partial dentures after gaining experience in the treatment of edentulous patients who required complete dentures. In the remaining schools $(87 \%)$, this order depended on the treatment prescribed for the respective randomly assigned patients. In thirteen schools (87\%), there was further teaching of RPD design and prescription writing. Further lectures on this topic were delivered by six (54\%) public (mean: 15 hours, range: 1-50 hours) and two (50\%) private schools (mean: 3 hours, range: 2-4 hours). Five public schools (45\%) reported supplementary tutorials and seminars on this topic (mean: 6.5 hours, range: $1-12$ hours), as did two private (50\%) schools (mean: 3 hours, range: $2-4$ hours). Students in seven public $(64 \%)$ and two private $(50 \%)$ schools did not use a surveyor when designing RPDs. A wide variety of impression-making techniques were taught for making master/ secondary impressions, including various combinations of impression trays and materials (Table 4). Both metallic and special trays were widely taught, as were alginate (irreversible hydrocolloid) and polyvinylsiloxane. No schools taught students to use plastic stock trays when recording master impressions.

Thirteen (87\%) respondent schools only worked with external dental laboratories. The remaining two public $(13 \%$ of the total) dental schools used both internal

Table 4. Combinations of impression trays and materials taught to make master/secondary impressions for RPDs.

Combination of impression trays and materials for RPDs

\begin{tabular}{|c|c|c|c|}
\hline & Public & Private & Total \\
\hline Metal stock tray plus alginate & 6 & 2 & 8 \\
\hline Special tray plus polyvinylsiloxane & 6 & 1 & 7 \\
\hline Special tray plus polyether & 6 & 1 & 7 \\
\hline Metal stock tray plus polyvinylsiloxane & 5 & 1 & 6 \\
\hline Metal stock tray plus polyether & 4 & 1 & 5 \\
\hline Special tray plus alginate & 5 & - & 5 \\
\hline
\end{tabular}


and external laboratories. Public schools required a minimum number of RPDs to be made per student as a prerequisite for graduation (mean: one of each type of prosthetic material, acrylic and cobalt-chromium). In private schools, although it is not mandatory for the students to complete any acrylic RPD prior to graduation; they must complete at least 2 cobalt-chromium RPDs. It was reported that the mean number of RPDs made per student prior to graduation in public schools was 3.4 acrylic (range: 1-20) and 3.4 cobalt-chromium (range: 1-20) RPDs. The corresponding figures reported for private schools was 1 acrylic (range: $0-2$ ), and 2.3 cobalt-chromium (range: 1-4) RPDs.

Six public $(54 \%)$ and one private $(25 \%)$ dental school informed that they found their pool of patients unsuitable for student treatment. The reasons for this included difficult dental configurations (e.g., tooth wear), socially complicated patients, lack of sufficient appropriate patients for RPD-treatments, patients demanding conventional fixed or implant-supported prostheses; and lack of time to carry out these treatments at the dental school. The items examined in different schools for clinical abilities concerning RPDs are displayed in table 3 . The general assessments were surveying and design (87\% schools), mounting casts in an articulator (80\% schools) and prescription writing ( $80 \%$ schools).

The most common challenges reported to the teaching of removable partial dentures over the next few years were the lack of suitable patients mainly due to the decreased demand for RPDs (60\% schools), and pressures on teaching time from other sources (53\% schools).

\section{Discussion}

Spain has a total land area of $505954 \mathrm{~km}^{2}$. This country has a population of 45061275 inhabitants, and it has been estimated that $90 \%$ of the Spanish partially dentate population are more than 50 years old. The number of dentists working in Spain has increased by $102 \%$ in the last 15 years, from 13242 dentists in 1994 to 26 725 in 2009, the majority of whom work in the private sector (data from the Spanish National Institute of Statistics: INE). The Ministry of Health regulates the dental profession, so that no dentist can practice Dentistry in Spain unless s/he has passed the state's re-validation exam in case the title had been obtained overseas. All dentists working in Spain have to be registered in the Official Association for Dentists, but recently qualified dentists are not obliged to complete any training programme before starting independent professional practice in Spain. Patients pay for treatments in both public and private dental schools.

One important form of dental treatment in which one would expect newly qualified dentists to be competent -regardless of place of training - is the rehabilitation of partially dentate adults, including the provision of re- movable partial dentures. However, the findings of this survey -similar to those of previous studies developed in US $(16,17)$ and in Ireland and the UK (18)-, illustrate the wide variations between individual schools in the amount and content of teaching programmes. The average duration of the preclinical course was 76 hours in the US (17), 67 hours in Ireland and the UK (18), and 44 hours in Spain.

Disparities within European dental schools have also been identified in the teaching of endodontics (23) and direct composite restorations (24), and should be encouraged as they addresses the different disease expression, culture, and traditions of the EU states (23). Some regional variety in teaching may be, to an extent, unavoidable. Nonetheless, since European and therefore, Spanish qualified dentists may work worldwide; diversity in teaching must not be as great as to cause confusion amongst dentists, or even barriers to care for patients.

The current study illustrates discrepancies regarding the preclinical amount and content of teaching on removable partial dentures within and between public and private Spanish dental schools. Examples of this include the preclinical course duration, ranging from a minimum of 12 hours to a maximum of 120 hours. An important finding to consider is that the "hands-on" practical preclinical course on RPDs in the private schools was twice as long as in the public dental schools. This fact could be correlated to the differences in staff: student ratios between public and private dental schools, although dental students in the private schools seemed to complete fewer treatments than those in the public schools.

Another important finding of this survey is that students do not gain experience at tooth preparations on phantom-heads in nine of the surveyed schools $(60 \%)$. Preclinical stages should be viewed as preparatory courses for clinical practice, not merely technical exercises that are divorced from clinical reality. Rest seat preparations are essential for RPDs to avoid disturbance to the existing occlusal scheme. There is much to be gained in terms of developing student confidence in this important area prior to treating patients. Evidence from general dental practice suggests that dentists do not always complete optimum rest seat preparations prior to making RPDs, resulting in either inferior quality prostheses or adversely affecting the occlusion of patients receiving this treatment $(25)$.

In seven public (64\%) and two private (50\%) dental schools, undergraduate students did not routinely use a surveyor when designing their removable partial dentures. This is in accordance with a previous investigation carried out in British dental laboratories, in which only $9 \%$ of the RPD prescriptions received included surveyed preliminary casts (8). Nevertheless, it is a 
more serious cause of concern that most students $(87 \%$ of dental schools) need to be further taught in prescription writing in clinical stages, taking into account the importance of transmitting adequate design information to the technician (8). Such results are consistent with those of a former study, in which two-thirds of the surveyed vocational dental practitioners (graduated dentists who complete a year of supervised training before entering independent practice) in Ireland and the $\mathrm{UK}$, left the design of cobalt-chromium RPDs to technicians (26). In that study, when asked which part of making a cobalt-chromium RPD they found most difficult, $70 \%$ of respondents indicated that their problems related to designing and surveying (26). Owing to he lack of proper instruction, the practice of devolving prescribing discretion to the dental technician is still evident. However, the technician does not have access to crucial information relating to the nature and health of the periodontal tissues (10), and therefore, the potential for tissue damage is increased (8).

While the mean numbers of RPDs completed by dental students in Spain could be considered to be low - public schools: 3.4 acrylic (range: $1-20$ ) and 3.4 cobalt-chromium RPDs (range: 1-20); and private schools: 1 acrylic (range: 0-2) and 2.3 cobalt-chromium RPDs (range: 1-4)-, comparable data from the Ireland and UK dental schools were obtained, so that the average numbers of RPDs made by students prior to graduation was 2 acrylics (range: $0-3$ ) and 3 cobalt-chromium (range: 2-5) (18). Furthermore, in the US, although the average duration of the preclinical course was higher than that of Ireland/ UK and Spain, students were required to complete a related number of removable partial dentures in clinical stages (3 RPDs, range: 1-6) (1)".

The numbers of RPDs completed in dental schools is reducing from what it was approximately 30 years ago (27), which is also a reflection in trends towards increased tooth retention and the development of more predictable implant-retained prostheses.

Similar to that noted in Ireland and the UK, the current study revealed a reliance on part-time visiting general dental practitioners (e.g., Associate Professors) to support the delivery of teaching programmes. Whilst this can represent an advantage to introduce alternative approaches to clinical treatments, it is important to avoid inter-teacher variation thus guaranteeing the harmonization of the dental school teaching programmes (18).

In a time of increasingly adverse staff: student teaching ratios, more "traditional" teaching methods will suffer. Despite this, it is encouraging to remark that fourteen $(93 \%)$ respondent schools still undertake live demonstrations of clinical RPD teaching in relatively small groups. In dealing with contemporary challenges, schools should consider the use of alternative teaching methods such as virtual and on-line teaching by means of recording and display of teaching programmes. Besides, there are some open websites containing online videos including different prosthetic procedures (e.g. www.aamc.org/mededportal). Within the frame of evolution towards self-directed student learning, videotaped recordings have been reported to be as effective as live demonstrations for understanding the principal subjects of RPD treatments, such as impressions making (28).

Diverse interactive multimedia resources have been described, such as computer generated cases for designing RPDs. These computer programs may advance students' confidence and ability efficiently and rapidly by simulation, so that precious human interaction time can be used at higher level and to maximum effect (14). Regrettably, the requirement of adequately prepared staff and high cost of multimedia resources pose impediments in some dental schools having restricted financial recourses.

Comparable disparities on teaching methods were found in a study developed in the public dental schools of Ireland and the UK (18), and have been reported to be a reflection of the current pressures on contemporary dental education, with increased student numbers and limited availability of suitable staff $(29,30)$. This may help explain why divergences in the amount and content of teaching on removable partial dentures among dental schools increase progressively over time $(18,27)$. As it has been mentioned, variations are not exclusively of this subject, and have also been detected in other areas in contemporary restorative dentistry (24). Notwithstanding this, dental school educators must remain vigilant to avoid diminution of the quality of their teaching programmes. Since dental students of 2009/10 will continue to practice dentistry into the mid 2050s, the teaching they receive in contemporary education will influence their approaches to treatment over many years to come (18).

This paper found a wide variation within and between public and private Spanish dental schools regarding the teaching programmes and clinical skills on RPDs achieved by undergraduate students. Therefore, as recommended in other surveyed countries, efforts must be made to promote harmonization of dental curricula among Spanish dental schools. This will make it easier for graduates to work elsewhere, and to ensure they meet the needs of their patients on entering independent practice.

\section{References}

References with links to Crossref - DOI

1. Petropoulos VC, Rashedi B. Removable partial denture education in U.S. dental

schools. J Prosthodont. 2006;15:62-8.

2. Douglass CW, Watson AJ. Future needs for fixed and removable partial dentures in the United States. J Prosthet Dent. 2002;87:9-14.

3. Vanzeveren C, D’Hoore W, Bercy P, Leloup G. Treatment with re- 
movable partial dentures: a longitudinal study. Part I. J Oral Rehabil. 2003;30:447-58.

4. Walton JN, MacEntee MI. Choosing or refusing oral implants: a prospective study of edentulous volunteers for a clinical trial. Int $\mathbf{J}$ Prosthodont. 2005; 18:483-8.

5. Leles CR, Martins RR, Silva ET, Nunes MF. Discriminant analysis of patients' reasons for choosing or refusing treatments for partial edentulism. J Oral Rehabil. 2009;36:909-15.

6. Basker RM, Harrison A, Davenport JC, Marshall JL. Partial denture design in general dental practice--10 years on. Br Dent J. 1988; 165:245-9.

7. Lynch CD, Allen PF. A survey of chrome-cobalt RPD design in Ireland. Int J Prosthodont. 2003;16:362-4.

8. Lynch CD, Allen PF. Quality of written prescriptions and master impressions for fixed and removable prosthodontics: a comparative study. Br Dent J. 2005;198:17-20.

9. Kilfeather GP, Lynch CD, Sloan AJ, Youngson CC. Quality of communication and master impressions for the fabrication of cobalt chromium removable partial dentures in general dental practice in England, Ireland and Wales in 2009. J Oral Rehabil. 2010;37:300-5. 10. Schwarz WD, Barsby MJ. A survey of the practice of partial denture prosthetics in the United Kingdom. J Dent. 1980;8:95-101.

11. Radhi A, Lynch CD, Hannigan A. Quality of written communication and master impressions for fabrication of removable partial prostheses in the Kingdom of Bahrain. J Oral Rehabil. 2007;34:153-7.

12. Schwarz WD, Barsby MJ. Design of partial dentures in dental practice. J Dent. 1978;6:166-70.

13. Owall B, Budtz-Jörgensen E, Davenport J, Mushimoto E, Palmqvist $\mathrm{S}$, Renner R, et al. Removable partial denture design: a need to focus on hygienic principles? Int J Prosthodont. 2002;15:371-8.

14. Lechner SK, Thomas GA, Bradshaw M. An interactive multimedia solution to learning removable partial denture design. J Prosthodont. 1998; 7:177-82.

15. Jepson NJ, Thomason JM, Steele JG. The influence of denture design on patient acceptance of partial dentures. Br Dent J. 1995; 178:296-300.

16. Sukotjo C, Thammasitboon K, Howell H, Karimbux N. Students' perceptions of prosthodontics in a PBL hybrid curriculum. J Prosthodont. 2008;17:495-501.

17. Rashedi B, Petropoulos VC. Preclinical removable partial dentures curriculum survey. J Prosthodont. 2003;12:116-23.

18. Lynch CD, Allen PF. The teaching of removable partial dentures in Ireland and the United Kingdom. Br Dent J. 2007;203:E17.

19. Yip HK, Smales RJ. Review of competency-based education in dentistry. Br Dent

J. 2000;189:324-6.

20. Nicolas E, Baptiste M, Roger-Leroi V. Clermont-Ferrand dental school curriculum: an appraisal by last-year students and graduates. Eur J Dent Educ. 2009;13:93-9.

21. Sanz M. Dental education and the Bologna Process. Eur J Dent Educ. 2003;7:143-6.

22. Sanz M, Widström E, Eaton KA. Is there a need for a common framework of dental specialties in Europe? Eur J Dent Educ. 2008;12:138-43.

23. Gatley S, Hayes J, Davies C. Requirements, in terms of root canal treatment, of undergraduates in the European Union: an audit of teaching practice. Br Dent J. 2009;207:165-70.

24. Wilson NH, Mjör IA. The teaching of Class I and Class II direct composite restorations in European dental schools. J Dent. 2000;28:15-21.

25. Rice JA, Lynch CD, McAndrew R, Milward PJ. Tooth preparation for rest seats for cobalt-chromium removable partial dentures completed by general dental practitioners. J Oral Rehabil. 2011;38:72-8. 26. Lynch CD, Allen PF. Why do dentists struggle with removable partial denture design? An assessment of financial and educational issues. Br Dent J. 2006;200:277-81.

27. Barsby MJ, Schwarz WD. A survey of the teaching of partial denture construction in dental schools in the United Kingdom. J Dent. $1979 ; 7: 1-8$.
28. Packer ME, Rogers JO, Coward TJ, Newman PS, Wakeley R. A comparison between videotaped and live demonstrations, for the teaching of removable partial denture procedures. Eur J Dent Educ. 2001;5:17-22.

29. Lynch CD, McConnell RJ, Wilson NH. Challenges to teaching posterior composites in the United Kingdom and Ireland. Br Dent J. 2006;201:747-50.

30. Kay EJ, O’Brien KD. Academic dentistry--where is everybody? Br Dent J. 2006;200:73-4.

\section{Acknowledgments}

The authors gratefully acknowledge the assistance of all those who completed the questionnaire. 